\title{
OCORRÊNCIA E DISTRIBUIÇÃO GEOGRÁFICA DO BACURIZEIRO ${ }^{1}$
}

\author{
WALNICE MARIA OLIVEIRA DO NASCIMENTO², \\ JOSÉ EDMAR URANO DE CARVALHO², CARLOS HANS MÜLLER ${ }^{2}$
}

RESUMO - O bacurizeiro é espécie frutífera promissora, devido as amplas possibilidades que apresenta como planta de uso múltiplo (madeira e fruto), podendo vir a se constituir, em breve, em nova alternativa de cultura perene para a Amazônia. A ocorrência e a distribuição geográfica do bacurizeiro, apresentadas neste trabalho, baseiam-se em grande parte nos levantamentos sobre vegetação efetuados pela Comissão Executora do Projeto Radambrasil, por levantamentos em herbários, além de informações em inventários florísticos contidos na literatura. O objetivo deste trabalho foi registrar a distribuição geográfica do bacurizeiro, visando a estudos de disponibilidade genética e coleta de material para definir procedimentos adequados para seu cultivo e conseqüente redução de pressão sobre as populações nativas. Não existem dúvidas sobre a origem amazônica do bacurizeiro, sendo encontrado, no início do século vinte, tanto na margem esquerda como na margem direita do Rio Pará, abundante na costa sudeste da ilha do Marajó, onde se constitui em árvore característica das matas marginais. Em toda a Amazônia, a área de maior concentração da espécie é o estuário do Rio Amazonas. Do Estado do Pará, dispersou-se em direção ao nordeste do Brasil, alcançando os cerrados e chapadões dos Estados do Maranhão e Piauí. Na direção sul, a dispersão atingiu os Estados de Tocantins e Mato Grosso, chegando a romper as fronteiras do Brasil. Na direção norte, atingiu o Estado do Amapá, ocorrendo também, embora de forma rara, no Estado do Amazonas.

Termos para indexação: dispersão, frutífera nativa, população, Platonia insignis Mart .

\section{OCCURRENCE AND GEOGRAPHICAL DISTRIBUTION OF BACURI}

\begin{abstract}
The Platonia insignis is a promising fruit species, for the wide possibilities that it presents as species of multiple purposes, and soon could become a new alternative of perennial culture for the Amazon region. The occurrence and geographical distribution of the $P$. insignis presented in this work, is largely based on the appointments on vegetation made by the project Radambrasil, research in herbarium, besides information in gardening inventories contained in the literature. The objective of this work was to register information about the geographical distribution of the $P$. insignis, seeking studies of genetic disposal and collects of material to define appropriate procedures for its cultivation and consequent pressure reduction on native plant populations. There aren't doubts on the Amazon origin of the P. insignis, being found in the beginning of the twentieth century, in the left margin and in the right margin of the Pará river, abundant in the southeast coast of Marajó Island, where constitute in a characteristic tree of marginal forests. In all Amazon, one area of large concentration of the species is the estuary of Amazon's river. In the State of Pará, was dispersed in direction to the northeast of Brazil, reaching the savannahs and plains of the States of Maranhão and Piauí. In the south direction, the dispersion reached the States of Tocantins and Mato Grosso, getting to break the borders of Brazil. In the north direction it reached the State of Amapá, also happening, although in a rare way, in the State of Amazon.
\end{abstract}

Index terms: dispersion, native fruit, population,Platonia insignis Mart.

O bacurizeiro (Platonia insignis Mart.) é espécie arbórea nativa da Amazônia, sendo seu provável centro de diversidade genética o Estado do Pará (Cavalcante, 1996). Os frutos dessa espécie pelo sabor e aroma peculiar, são bastante utilizados para elaboração de suco, sorvete, creme, doce, compota ou mesmo consumidos in natura pela população da Amazônia e de parte do Nordeste do Brasil, particularmente nos Estados do Maranhão e Piauí, onde é também encontrado em estado nativo (Figura 1).

$\mathrm{O}$ fruto do bacurizeiro ocupa posição de destaque na preferência dos consumidores de Belém, enquadrando-se, juntamente com o açaí, cupuaçu, pupunha, abacaxi e a graviola, como os de maior aceitação dentre os frutos nativos da Amazônia (Cavalcante, 1996). Na Amazônia brasileira a polpa congelada de bacuri atinge o mais alto preço, independentemente da época do ano, quando comparada com produto similar de outras frutas tropicais. Não obstante, a produção de frutos é decorrente, na quase totalidade, de atividade extrativista, sendo raros os pomares com essa espécie. Tal fato é devido às dificuldades de propagação, ao longo período de juvenilidade da planta, que pode alcançar mais de 10 anos para o início da frutificação, especialmente quando propagada por sementes, e ao baixo rendimento de polpa. No início da década de 40, Pesce (1941) já chamava a atenção para o

${ }^{1}$ (Trabalho157-06). Recebido em :10-10-2006. Aceito para publicação em: 28-05-2007

${ }^{2}$ Pesquisadores da Embrapa Amazônia Oriental, Belém- PA CEP 66095-100, walnice@cpatu.embrapa.br, urano@cpatu.embrapa.br, hans@cpatu.embrapa.br

Rev. Bras. Frutic., Jaboticabal - SP, v. 29, n. 3, p. 657-660, Dezembro 2007 
fato de que a planta não era cultivada, devido ao seu desenvolvimento demorado, conquanto, já naquela época, os frutos eram muito procurados pelas fábricas de doces, bem como consumidos pela população.

Embora a espécie Platonia insignis seja mais conhecida como planta frutífera, o bacurizeiro também apresenta madeira com boa característica físico-mecânica e multiplicidade de usos, podendo ser utilizada na fabricação de móveis, caibros, ripas, estacas, dormentes, embalagens pesadas e tacos (Loureiro et al., 1979; Mainieri \& Loureiro, 1964; Mainieri \& Chimelo, 1989; Paula \& Alves, 1997). Convém ressaltar que, no pólo madeireiro de Paragominas-PA, segundo Lisboa et al. (1991), o volume de madeira serrada dessa espécie, no final dos anos 80, superava aos de outras essências florestais bem mais conhecidas, tais como o marupá (Simaruba amara), a andiroba (Carapa guianensis) e o acapu (Vouacapoua americana).

Além das possibilidades como planta frutífera e madeireira, as sementes podem ser utilizadas para extração de óleo, dando ainda como subproduto, farelo, com $16 \%$ de proteína (Pesce, 1941). O aproveitamento, tanto do óleo como do farelo, ainda necessita de pesquisas que definam procedimentos adequados para a remoção da substância resinosa presente nas sementes, que conferem ao óleo extraído a coloração escura, e ao farelo, sabor um tanto quanto amargo. Nos últimos anos, o bacurizeiro tem sido freqüentemente citado como espécie promissora, pelas amplas possibilidades que apresenta como espécie de uso múltiplo (Prance, 1992; Moraes et al., 1994; Villachica et al., 1996), podendo vir a se constituir, em breve, em nova alternativa de cultura perene para a Amazônia. Para tanto, é necessário que se intensifiquem os trabalhos de pesquisa concernentes à coleta e avaliação de germoplasma, métodos de propagação, sistemas reprodutivo, técnicas de cultivo e processamento do fruto, de tal forma que culminem com a domesticação da espécie. O objetivo do trabalho foi de registar a distribuição geográfica do bacurizeiro, visando a estudos de disponibilidade genética e coleta de material para definir procedimentos adequados para o seu cultivo e conseqüente redução da pressão sobre as populações nativas.

Na concepção de Huber (1904), não existem dúvidas sobre a origem amazônica do bacurizeiro, assinalando ainda que, no início do século vinte, era encontrado tanto na margem esquerda como na margem direita do Rio Pará, sendo abundante na costa sudeste da ilha do Marajó, onde se constitui em árvore característica das matas marginais e dos tesos e campos altos. Cavalcante (1996) postulava a origem paraense, pelo fato de que, em toda a Amazônia, a área de maior concentração da espécie é o estuário do Rio Amazonas, com ocorrência mais acentuada na microrregião do Salgado e na ilha do Marajó, principalmente na microrregião do Arari. Nesses locais, o bacurizeiro prolifera em tal intensidade, formando maciços, que praticamente domina a fisionomia da paisagem, chegando, em alguns casos, a ser considerada invasora de difícil erradicação, haja vista sua notável capacidade de regeneração, tanto a partir de sementes como por brotação de raízes (Calzavara, 1970; Cavalcante, 1996). A regeneração a partir de brotações de raízes é particularmente exuberante após a derrubada da planta-mãe, em alguns casos, após a derrubada simultânea de diversas árvores, as brotações chegam a cobrir completamente a superfície do solo.

Do Estado do Pará, segundo Cavalcante (1996), dispersouse em direção do nordeste do Brasil, alcançando os cerrados e chapadões dos Estados do Maranhão e do Piauí, onde também forma povoamentos relativamente densos. $\mathrm{Na}$ direção sul, a dispersão atingiu o Paraguai. Na direção norte o Estado do Amapá, a Guiana Francesa, o Suriname e a Guiana, ocorrendo também, embora de forma rara, no Estado do Amazonas.

$\mathrm{Na}$ distribuição proposta por Cavalcante (1996), alguns pontos merecem consideração especial, particularmente no que concerne à presença da espécie no Paraguai e a não- consideração de áreas onde é encontrada em estado nativo. Estudos efetuados nas cartas elaboradas pela Comissão Executora do Projeto Radambrasil, em herbários, em levantamentos florísticos efetuados em diversas regiões da Amazônia, indicam dispersão bem mais ampla, chegando a atingir os Estados de Roraima e Acre, não sendo tão inexpressiva a ocorrência no Estado do Amazonas (Brasil, 1975; 1977). Nesses locais, o bacurizeiro é encontrado em áreas de floresta densa, com densidade muito inferior a um indivíduo por hectare, o que é comum quando a espécie ocorre em floresta primária. Considerando-se os locais em que efetivamente há registro de ocorrência da espécie em estado espontâneo, pode-se admitir a distribuição geográfica apresentada na Figura 2.

O bacurizeiro é predominantemente encontrado na mesorregião Nordeste Paraense, sendo particularmente abundante nas microrregiões do Salgado, Bragantina e Cametá e mais raramente nas microrregiões de Tomé-Açu e Guamá; na mesorregião Marajó, é mais freqüente na microrregião Arari. Embora em abundância, na mesorregião Nordeste Paraense, as plantas encontram-se mais dispersas, com densidade de 50 a 100 indivíduos adultos por hectare. Já na mesorregião Marajó, é freqüentemente encontrada formando populações densas, geralmente com número de indivíduos adultos entre 100 e 200 ou até mais por hectare. Nas microrregiões do Salgado, Bragantina, Cametá e Arari, o bacurizeiro ocupa predominantemente áreas próximas ao ecossistema de campos naturais (Calzavara, 1970).

Na mesorregião metropolitana de Belém, a ocorrência é maior nas ilhas de Outeiro, Mosqueiro e Barcarena. Nesses locais, as plantas de bacurizeiro ocorrem predominantemente em áreas de vegetação aberta de transição (Cavalcante, 1996), enquanto nas mesorregiões do baixo Amazonas (microrregião de Santarém) e sudeste paraense (microrregião Tucuruí e Paragominas), é encontrado em áreas de floresta densa.

$\mathrm{Na}$ Amazônia brasileira, a dispersão atingiu os Estados do Acre, Amapá, Amazonas, Roraima e Tocantins. Nos quatro primeiros Estados, a ocorrência é sempre em áreas de floresta primária e com reduzidíssimo número de indivíduos por hectare. No Estado de Tocantins, a espécie Platonia insignis é encontrada tanto em áreas de floresta primária quanto em floresta secundária. Nesse último caso, é encontrada formando aglomerados, particularmente nos municípios de Araguatins, Tocantinópolis, Luzinópolis, Darcinópolis, Maurilândia e Cachoeirinha, todos no norte do Estado (Brasil , 1977).

Na direção da região nordeste do Brasil, a dispersão alcançou os Estados do Maranhão e do Piauí. No primeiro Estado, 
ocorre nas áreas limítrofes aos Estados do Tocantins, entre os municípios de Carolina e Imperatriz, acompanhando o curso dos rios Tocantins e Pará e continuando no curso do Rio Gurupi. Também é encontrada no município de São Luís e na região mais ao leste do Estado, particularmente nos municípios de Mirador, Matões, Timo, Caxias, Aldeias altas e Coelho Neto dentre outros. No Estado do Piauí, a distribuição do bacurizeiro está limitada à região norte do Estado, ocorrendo com maior freqüência nos municípios de Luizilândia, Batalha, Barras, Matias Olímpio e Campo maior. Em muitos sítios de ocorrência do bacurizeiro, ou em áreas próximas, nos Estados do Piauí e principalmente do Maranhão, são encontradas outras espécies da Hiléia Amazônica, em particular dos táxons Cecropia, Cedrela, Copaifera, Dipteryx, Genipa, Lecythis, Parkia e Schizolobium (Brasil, 1975, 1977).

Nos Estados do Ceará e de Pernambuco, são encontrados alguns exemplares de Platonia insignis isolados, particularmente nas serras úmidas (Braga, 1976; Guimarães et al., 1993), mas provavelmente não são produtos de dispersão natural e, sim, de introduções efetuadas por nordestinos que, durante o ciclo da borracha, dirigiram-se para a Amazônia e, ao retornarem, levaram sementes ou mudas de algumas espécies dessa região. Tal afirmativa é baseada no fato de que, nesses dois Estados, particularmente no Ceará, os indivíduos encontrados estão isolados, normalmente em áreas com forte ação antrópica, convivendo com outras espécies nativas da Amazônia, como, por exemplo: o cacaueiro (Theobroma cacao L.), a pupunheira (Bactris gasipaes Kunth) e a seringueira (Hevea brasiliensis), e mesmo com espécies exóticas cultivadas na Amazônia, como é o caso do abricoteiro (Mammea americana L.) e da pimenteira-doreino (Piper nigrum L.).

Rompendo as fronteiras do Brasil, o bacurizeiro é encontrado, embora de forma rara, na Amazônia peruana, venezuelana, colombiana e na Guiana Francesa. Com relação à ocorrência no Paraguai, não há registros que comprovem a presença da espécie, tanto em estado nativo como cultivado, podendo-se admitir que, na direção sul, a dispersão atingiu somente o Estado do Mato Grosso, onde são encontrados diminutos números de indivíduos, nas margens do Rio Guaporé, conforme constatou Macedo (1995), havendo também o registro em herbário de coleta de material botânico no município de Poconé (MT). No Paraguai, ocorre uma espécie que também recebe a denominação de bacuri, mas trata-se de uma Arecaceae, com denominação científica de Attalea phalerata (Lorenzi et al., 1996).

De acordo com o mapa de tipos climáticos da Amazônia, citado por Bastos (1982), o bacurizeiro concentra-se principalmente em regiões com tipos climáticos Ami (clima de transição entre Afi e Awi, com estação seca de dois a três meses, porém com precipitação pluviométrica igual ou superior a $2.000 \mathrm{~mm}$ anuais) e clima Awi (com nítida estação seca de cinco a seis meses, e precipitação pluviométrica anual inferior a $2.000 \mathrm{~mm}$ ), embora ocorrendo em pequena concentração em clima Afi (precipitação pluviométrica anual superior a $2.000 \mathrm{~mm}$ ), segundo a classificação de Köeppen.

Até o início da década de 80, essa Clusiaceae foi considerada espécie com riscos mínimo de erosão genética, tendo em vista a característica de emitir abundantes brotações de raízes, mesmo após a derrubada da planta-mãe. No entanto, já no final da década de 80 e início da década de 90 , a utilização do bacurizeiro com finalidade madeireira começou a colocar em risco seu patrimônio genético. Além disso, em áreas onde se concentram importantes populações de bacurizeiros, a atividade da pecuária tem impedido a regeneração natural das plantas, tanto pelo pisoteio quanto pelo pastejo das brotações oriundas de raízes. Mais recentemente, a expansão da área urbana de cidades situadas nas regiões litorâneas dos Estados dos Pará e Maranhão, onde a espécies ocorre formando maciços quase homogêneos, é outro fator que tem contribuído para o comprometimento da variabilidade genética do bacurizeiro. A coleta, a conservação ex situ e a avaliação de germoplasma constituem-se em atividade essencial para resguardar o patrimônio genético e para subsidiar programas de melhoramento que levem a sua completa domesticação.
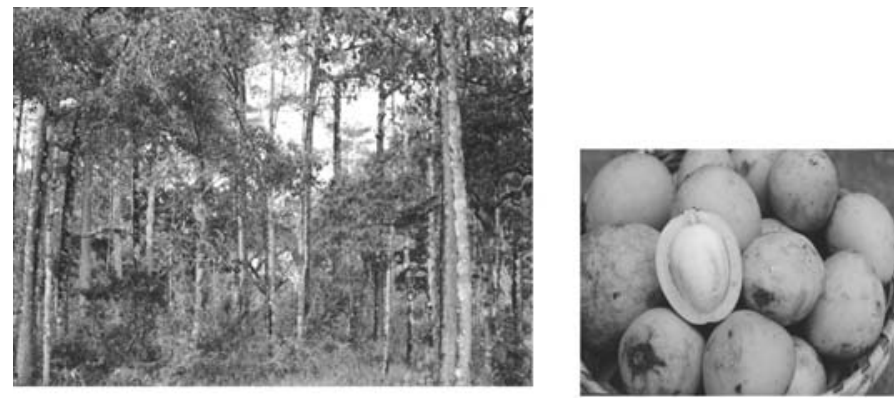

FIGURA 1 - Plantas e frutos de bacuri em área de vegetação secundária no município de Carutapera-MA.

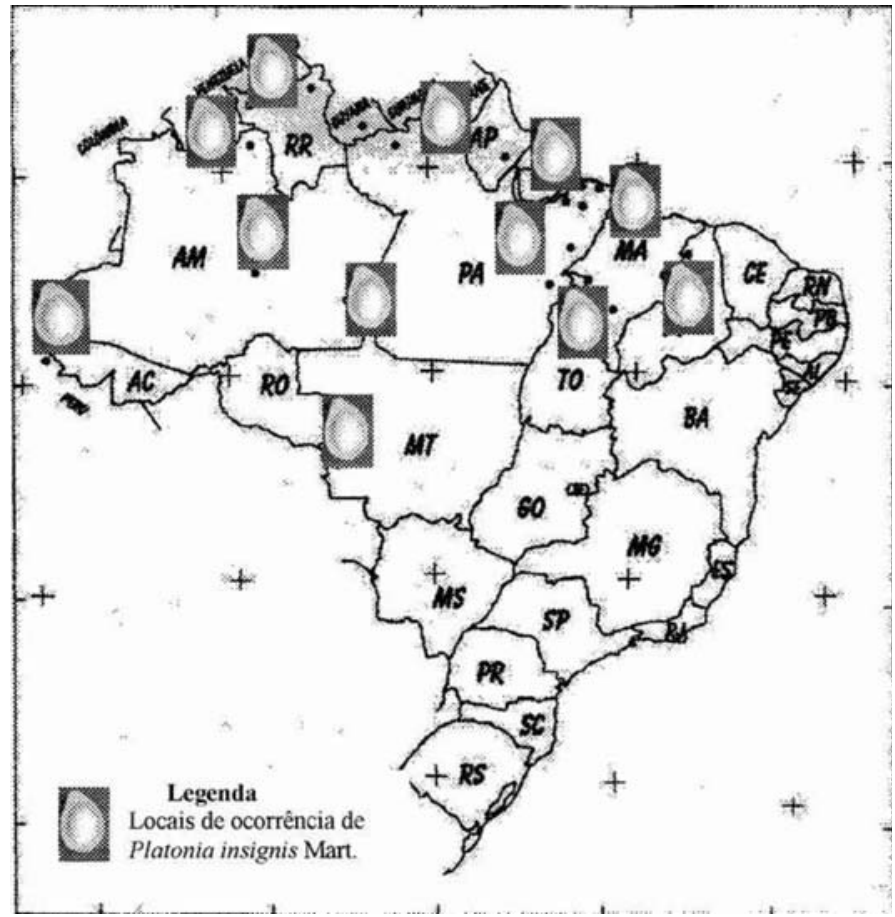

FIGURA 2 - Locais de ocorrência do bacurizeiro (Platonia insignis Mart.) 


\section{REFERÊNCIAS}

BRAGA, R. Plantas do nordeste especialmente do Ceará. Mossoró: ESAM, 1976. 540p.

BRASIL. Departamento Nacional de Produção Mineral. Projeto RADAMBRASIL. Folha NA.20. Boa Vista e parte da folha NA.21. Tumucumaque NB.20. Roraima e NB.21; geologia, geomorfologia, pedologia, solos, vegetação e uso potencial da terra: Rio de Janeiro. 1975. 428p. (Levantamento de Recursos Naturais, 8).

BRASIL. Departamento Nacional de Produção Mineral. Projeto RADAMBRASIL. Folhas B/SC.18. Javari/Contamana; geomorfologia, pedologia, solos, vegetação e uso potencial da terra: Rio de janeiro. 1977. 420p. (Levantamento de Recursos Naturais, 13)

BASTOS, T.X. O clima da Amazônia Brasileira segundo Köppen. Belém: EMBRAPA-CPATU, 1982. 4p. (EMBRAPA-CPATU. Pesquisas em andamento, 87).

CALZAVARA, B.B.G. Fruteiras: abieiro, abricozeiro, bacurizeiro, cupuaçuzeiro. Belém: IPEAN, v.1, n.2, 84p. 1970 (Série Culturas da Amazônia).

CAVALCANTE, P.B. Frutas comestíveis da Amazônia. Belém: Cejup, 6 ed. 1996.279p.

GUIMARÃES. E.F.; MAUTONE, L.; RIZZINI, C.T.; MATTOS FILHO, A. de Árvores do Jardim Botânico do Rio de Janeiro. Rio de Janeiro: Jardim Botânico, 1993. 198p.

HUBER, J. Notas sobre a pátria e distribuição geográfica das árvores ao Pará. Belém: Museu Paraense Emílio Goeldi de História Natural e Ethnografia, v.4, p.375-406, 1904. (Museu Paraense Emílio Goeldi de História Natural e Ethnografia. Boletim de Pesquisa, 4).

LISBOA, P.L.B.; TEREZO, E.F. DE M.; SILVA, J.C.A. do Madeiras amazônicas: considerações sobre exploração, expedição de espécies e conservação. Belém: Boletim de Pesquisa do Museu Paraense Emílio Goeldi, Belém, v.7, n.2, p.521-542, 1991.

LOUREIRO, A.A.; SILVA, M.F. da; ALENCAR, J. da C. Essências madeireiras da Amazônia. Manaus: CNPq/INPA, v.1, 1979. 245p.
LORENZI, H.; SOUZA, H.M.; COSTA, J.T. de M.; CERQUEIRA, L.S.C. de; BEHR, N. von Palmeiras no Brasil: nativas e exóticas. Nova Odessa: Editora Plantarum, 1996.303p.

MACEDO, M. Contribuição ao estudo de plantas econômicas no Estado do Mato Grosso. Cuiabá: UFMT, 1995. 70p.

MAINIERI, C.; LOUREIRO, A.A. Madeiras de Simphonia globulifera L. Platonia insignis Mart., Moronobea coccinea Aubl. E Moronobea pulchra Ducke (Gutiferaceae): estudo anatômico macro e microscópico, como contribuição para a sua identificação. Belém: CNPq/INPA, 1964. 27p. (CNPq/INPA. Publicação, 18).

MAINIERI, C.; CHIMELO, J.P. Fichas de características de madeiras brasileiras. São Paulo: IPT, 2ed. 1989, 418p.

MORAES, V.H. de F.; MÜLLER, C.H; SOUZA, A.G.C.de; ANTONIO, I.C. Native fruit species of economic potential from brazilian Amazon. Angewandfe Botanik, v.68, p. 4752, 1994.

PAULA, J.E. de; ALVES, J.L. de H. Madeiras nativa; anatomia, dendrologia, dendometria, produção e uso. Brasília: Empresa Gráfica Gutenberg LTDA, 1997.541p.

PESCE, C. Oleaginosas da Amazônia. Belém: Revista da Veterinária, 1941.130p.

PRANCE, G.T. The resource of useful tree species: identificação of priorities for domestication: Amazonian tree diversity and the potential for supply of of non-timber forest products. In: LEAKEY, R.R.B.; NEWTON, A.C. Tropical trees: the potential for domestication and the rebuilding of forest resources the proceedings of a Conference as part of the IUFRO Centennial yar. London: IUFRO/Edindurgh Centre for Tropical Forests/ITE, 1992. P.7-15 (ITE Symposium, 29. ECTF Symposium, 1)

VILLACHICA, H.; CARVALHO, J.E.U. de; MÜLLER, C.H.; DIAZ, S.C.; ALMANZA, M. Frutales y hortalizas promissores de la Amazonia. Lima: Tratado de Cooperacción Amazonica, 1996, p. 49-55 (SPT-TCA, 44). 